\title{
STUDI KESESUAIAN DAN STRATEGI PENGELOLAAN EKOWISATA PANTAI UNGAPAN, KABUPATEN MALANG UNTUK PENGEMBANGAN PARIWISATA BERKELANJUTAN
}

\author{
Nailul Insani ${ }^{1}$, Fauzi Ramadhoan A'rachman ${ }^{2}$, Putri Kusuma Sanjiwani ${ }^{3}$, Frisco \\ Imanuddin ${ }^{1}$
}

Diterima 27 Maret 2019, Dipublikasikan 30 April 2019

CPenulis (2019)

\begin{abstract}
One form of utilization of coastal and marine resources in Malang Regency is the development of coastal tourism areas. In this case the form of coastal tourism developed is coastal recreation activities. The purpose of this study was to analyze the suitability of recreational tourism and formulate a strategy for managing coastal tourism areas. This research was conducted at Ungapan Beach in Gajahrejo Village, Gedangan District, Malang Regency, East Java. The method used in this study is descriptive with quantitative and qualitative analysis techniques. The data used in this study are primary and secondary data. Primary data collection in this study uses rapid integrated survey of coastal natural resources, observation and interviews. Collection of secondary data comes from literature studies and documents from relevant agencies. The analysis technique used is the calculation of the Travel Suitability Index (in Indonesia means Indeks Kesesuaian Wisata $I K W)$ for recreation and the SOAR method. Based on the calculation of IKW, Ungapan Beach is an appropriate category that can be used as a coastal ecotourism area with a value of 93\%. The strategy that can be applied at Pantai Ungapan is to optimize all existing potential and the cooperation of all tourism stakeholders to realize sustainable tourism management. Sustainability development is an integrated and organized effort to develop quality of life by regulating the supply, development, utilization and maintenance of resources in a sustainable manner.
\end{abstract}

Keywords

Travel suitability indeks, Tourism management

\section{PENDAHULUAN}

Wilayah pesisir dan laut memiliki daya tarik pemandangan pantai yang indah, keaslian lingkungan dan pesona kehidupan bawah air yang dapat dimanfaatkan untuk pengembangan ekowisata pantai,. Pantai merupakan batas antara wilayah daratan dengan perairan laut atau bagian wilayah yang menjadi tempat air laut dengan pasang tertinggi dan surut (Domo, et al., 2017). Pantai merupakan salah satu objek wisata yang memiliki daya tarik bagi wisatawan karena wujud dan suasana yang variatif, dengan melandaskan pada aspek eksplorasi, konservasi, dan pengelolaan secara terpadu. Salah satu aspek pembangunan pada bidang ekowisata diharapkan mampu mewujudkan pengelolaan

\footnotetext{
${ }^{1}$ Jurusan Geografi Universitas Negeri Malang nailul.insani.fis@um.ac.id

2 Jurusan Geografi Universitas Negeri Jakarta

3 Jurusan Destinasi Pariwisata Universitas Udayana
} 
ekosistem secara berkelanjutan adalah melalui pengembangan ekowisata (Fandeli, 2000). Pengembangan pantai sebagai ekowisata merupakan jasa lingkungan dari alokasi sumberdaya yang cenderung akan memberikan manfaat pada kepuasan batin seseorang dikarenakan mengandung nilai estetika tertentu (Ali, 2004). Untuk tujuan wisata, pantai berpotensi dimanfaatkan mulai dari kegiatan pasif (berupa menikmati pemandangan) hingga aktif seperti jogging (Senoaji, 2009).

Kawasan ekowisata pantai perlu dikembangkan dengan konsep berwawasan lingkungan agar terwujud pariwisata berkelanjutan, tidak menimbulkan kerusakan pada lingkungan dan memberikan jaminan kehidupan layak bagi masyarakat di sekitarnya, baik sekarang maupun untuk yang akan datang. Prinsip dasar Pariwisata Berkelanjutan merujuk pada Renstra Kementerian Pariwisata dan Ekonomi Kreatif Republik Indonesia Tahun 20122024 adalah kegiatan memanfaatkan sumber daya lingkungan secara optimal sambil mempertahankan ekologi dan konservasi, menghormati keaslian budaya dan masyarakat dan memastikan keberlanjutan jangka Panjang. Pembangunan pariwisata berkelanjutan harus memanfaatkan sumber daya alam secara optimal sesuai daya dukung sehingga tidak menimbulkan kerusakan, menghormati sosial budaya masyarakat, memastikan manfaat ekonomi yang berkelanjutan serta terdistribusi secara adil pada seluruh stakeholders.

Ekowisata pantai ungapan merupakan salah satu wisata rekreasi pantai yang terletak di Desa Gajahrejo, Kecamatan Gedangan Kabupaten Malang, Jawa Timur. Letak pantai ini berdekatan dengan Pantai Bajulmati. Jarak pantai ungapan dari kota Malang $\pm 64 \mathrm{~km}$. Pantai Ungapan memiliki ciri yang unik dan berbeda dari pantai lain yang ada di Malang karena pantai ini berdekatan dengan muara sungai. Warna air yang ada di muara juga berbeda, air yang ada di muara sungai berwarna kehijauan sedangkan air di Pantai Ungapan berwarna biru. Pantai Ungapan memiliki gelombang yang cukup besar khususnya di pagi hari. Aspek yang penting dalam konsep pemanfaatan sumber daya alam untuk tujuan wisata adalah kesesuaian sumber daya dan strategi pengembangan kegiatan wisata

(Hutabarat, et al., 2009). Pengelola tidak boleh hanya memikirkan bagaimana meningkatkan jumlah pengunjung tetapi tidak menghiraukan kesesuaian yang sebenarnya menjadi acuan suatu kawasan wisata sehingga tetap lestari dan berkelanjutan. Kesesuaian wisata untuk kegiatan rekreasi pantai harus memperhatikan karakteristik lingkungan pantai tersebut. Tujuan penelitian ini untuk menganalisis kesesuaian wisata dan merumuskan strategi pengelolaan kawasan ekowisata pantai Ungapan, Kabupaten Malang.

\section{METODE}

Penelitian ini dilakukan pada bulan November 2018 di Pantai Ungapan, Desa Gajahrejo, Kecamatan Gedangan, Kabupaten Malang, Jawa Timur (Gambar 1). Metode penelitian ini menggunakan metode deskriptif dengan teknik analisis kuantitatif dan kualitatif. Data yang digunakan dalam penelitian ini adalah data primer dan sekunder. Pengumpulan data primer dalam penelitian ini menggunakan rapid integrated survey sumber daya alam wilayah pesisir, wawancara dan observasi. Rapid integrated survey dilakukan dengan cara pengukuran langsung di lapangan dilakukan untuk parameter biofisik pantai yang meliputi: morfologi wilayah pesesiran, tipe pantai, lebar pantai, material dasar perairan, kemiringan pantai, penutupan lahan, aspek-aspek oseanografi, proses-proses geomorfologi, dan pola pemanfaatan ruang wilayah pesisiran dan ketersediaan air tawar. Wawancara dilakukan 
terhadap responden yang meliputi pengelola, penjaga pantai, pengunjung, masyarakat sekitar, dan pelaku usaha. Observasi dilakukan dengan datang langsung ke lapangan dan mengamati kondisi Pantai Ungapan dan lingkungan sekitar. Pengumpulan data sekunder bersumber dari studi literatur dan dokumen dari instansi terkait di antaranya berupa buku, hasil penelitian, dokumen rencana tata ruang, tugas akhir, serta artikel di internet dan media massa..

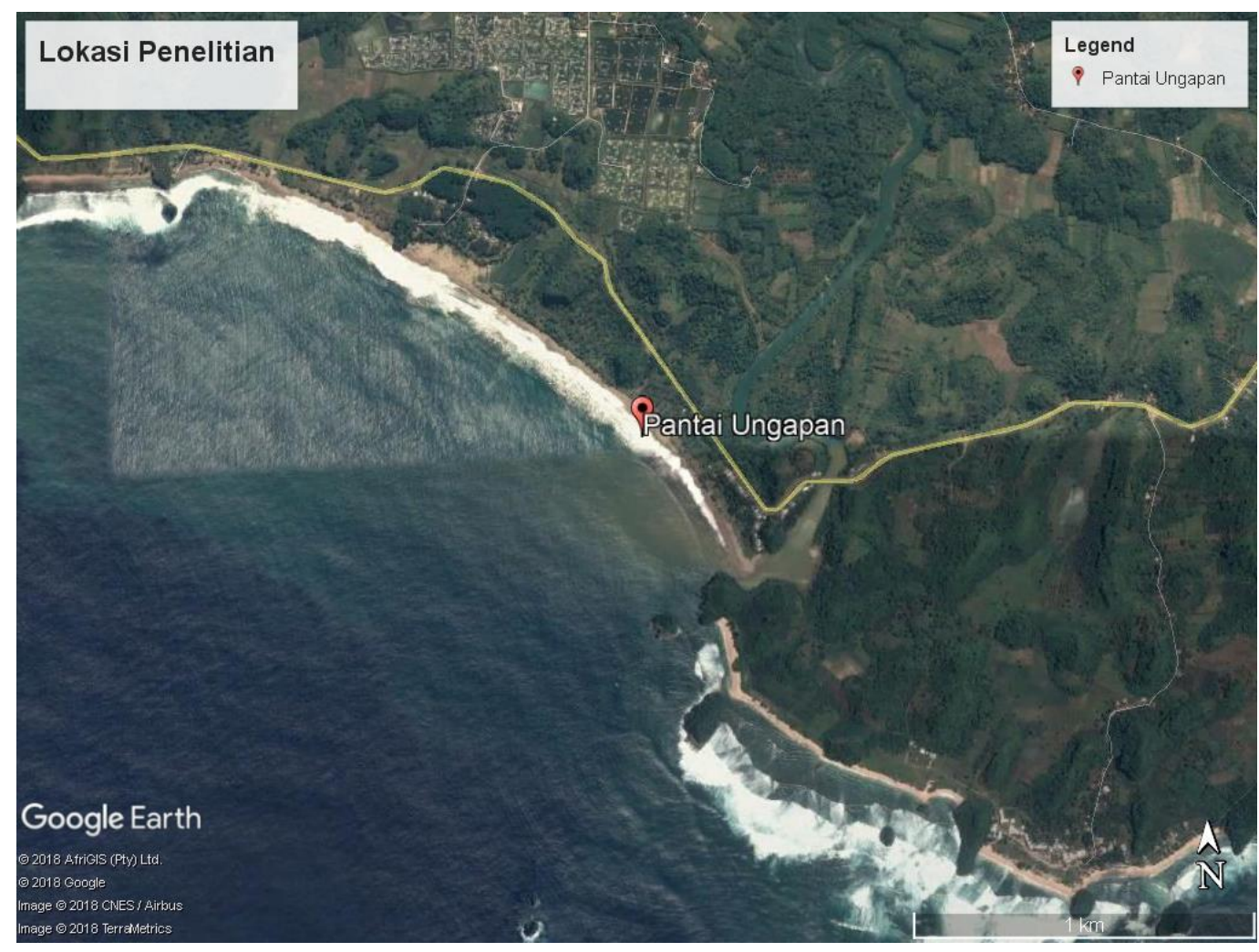

Gambar 1. Lokasi Penelitian di Pantai Ungapan (Google earth pro, 2018)

Teknik analisis yang digunakan yaitu perhitungan Indeks Kesesuaian Wisata (IKW) untuk rekreasi dan merumuskan strategi pengelolaan ekowisata dengan menggunakan analisis SOAR. Analisis kuantitatif digunakan untuk menghitung IKW dan metode kualitatif untuk strategi pengembangan metode SOAR dengan menerapkan prinsip pariwisata berkelanjutan. Analisis kesesuaian wisata menggunakan matriks kesesuaian yang disusun berdasarkan kepentingan setiap parameter untuk mendukung kegiatan pada daerah tersebut (Adi, et al., 2013). Berikut adalah formula untuk menganalisis kesesuaian wisata rekreasi pantai.

$$
\mathrm{IKW}=\Sigma\left(\frac{N i}{N \max }\right) x 100 \% \quad \text { (1) (Yulianda, 2007) }
$$

Keterangan:

IKW : Indeks Kesesuaian Wisata (rekreasi)

$\mathrm{Ni}$ : Nilai parameter ke-i (Bobot x Skor)

Nmaks : Nilai maksimum dari kategori wisata 
Selanjutnya dilakukan penyusunan kelas kesesuaian untuk kegiatan wisata rekreasi pantai. Dalam penelitian ini, Kelas kesesuaian lahan wisata rekreasi pantai dibagi dalam empat kelas kesesuaian, yaitu : Sangat Sesuai (S1) dengan persentase 80\% - 100\%, Sesuai (S2) dengan persentase $60 \%-<80 \%$, Sesuai Bersyarat (S3) dengan persentase $35 \%$ $<60 \%$, dan Tidak Sesuai (TS) dengan persentase <35\%. Definisi dari kelas-kelas kesesuaian dijelaskan pada tabel 1.

Tabel 1. Kategori nilai IKW

\begin{tabular}{cl}
\hline \multicolumn{1}{c}{ Kategori } & \multicolumn{1}{c}{ Keterangan } \\
\hline Kategori S1 & $\begin{array}{l}\text { Sangat Sesuai (Highly Suitable), pada kelas kesesuaian ini tidak mempunyai faktor } \\
\text { pembatas yang berat untuk suatu penggunaan tertentu secara lestari atau hanya mempunyai }\end{array}$ \\
& pembatas yang kurang berarti dan tidak berpengaruh secara nyata \\
Kategori S2 & Sesuai, pada kelas kesesuaian ini mempunyai faktor pembatas yang agak berat untuk suatu \\
& penggunaan kegiatan tertentu secara lestari. Faktor pembatas tersebut akan mempengaruhi \\
& produktivitas kegiatan wisata dan keuntungan yang diperoleh serta meningkatkan input \\
& untuk mengusahakan kegiatan wisata tersebut \\
& Sesuai Bersyarat, pada kelas kesesuaian ini mempunyai faktor pembatas yang lebih banyak \\
& untuk dipenuhi. Faktor pembatas tersebut akan mengurangi produktivitas sehingga untuk \\
& melakukan kegiatan wisata faktor pembatas tersebut harus benar-benar lebih diperhatikan \\
& sehingga ekosistem dapat dipertahankan \\
& Tidak Sesuai (Not Suitable), pada kelas kesesuaian ini mempunyai faktor pembatas berat \\
& atau permanen, sehingga tidak mungkin untuk mengembangkan kegiatan wisata secara \\
& lestari
\end{tabular}

Analisis strategi pengembangan menggunakan Analisis SOAR (Stavros \& Hinrichs, 2009) yang dilakukan untuk merumuskan strategi pengelolaan pengembangan kawasan ekowisata Pantai Ungapan. Analisis ini disusun dari faktor strategis yang menggambarkan kekuatan (strenght) dan peluang (opportunities) yang dihadapi dapat disesuaikan dengan aspirasi (aspirations) sehingga memperoleh hasil (results) yang terukur. Dalam kerangka kerja analisis SOAR didasarkan pada integritas melakukan inventarisasi faktor kekuatan, peluang, dan aspirasi yang selanjutnya mampu merumuskan hasil yang terukur sebagai alternatif strategi (lihat tabel 2 untuk memahami matriks pembobotan nilai IKW).

Tabel 1. Matriks IKW kategori rekreasi wisata pantai

\begin{tabular}{|c|c|c|c|c|c|c|c|c|c|}
\hline Parameter & Bobot & S1 & Skor & S2 & Skor & S3 & Skor & Sn & Skor \\
\hline Tipe Pantai & 5 & $\begin{array}{l}\text { Pasir } \\
\text { putih }\end{array}$ & 4 & $\begin{array}{l}\text { Pasir } \\
\text { putih, } \\
\text { karang }\end{array}$ & 3 & $\begin{array}{c}\text { Pasir } \\
\text { hitam, } \\
\text { karang } \\
\text { terjal }\end{array}$ & 2 & $\begin{array}{c}\text { Lumpur, } \\
\text { berbatu, } \\
\text { karang terjal }\end{array}$ & 1 \\
\hline $\begin{array}{l}\text { Lebar pantai } \\
\text { (m) }\end{array}$ & 5 & $>15$ & 4 & $10-15$ & 3 & $3-<10$ & 2 & $<3$ & 1 \\
\hline $\begin{array}{l}\text { Material dasar } \\
\text { Perairan }\end{array}$ & 5 & Pasir & 4 & $\begin{array}{l}\text { Karang } \\
\text { berpasir }\end{array}$ & 3 & $\begin{array}{c}\text { Pasir } \\
\text { berlump } \\
\text { ur }\end{array}$ & 2 & Lumpur & 1 \\
\hline $\begin{array}{l}\text { Kemiringan } \\
\text { pantai }(\%)\end{array}$ & 4 & $<10$ & 4 & $10-25$ & 3 & $>25-45$ & 2 & $>45$ & 1 \\
\hline $\begin{array}{l}\text { Penutupan } \\
\text { lahan pantai }\end{array}$ & 3 & $\begin{array}{l}\text { Kelapa, } \\
\text { lahan } \\
\text { terbuka }\end{array}$ & 4 & $\begin{array}{c}\text { Semak } \\
\text { belukar, } \\
\text { savana } \\
\text { rendah }\end{array}$ & 3 & $\begin{array}{l}\text { Belukar } \\
\text { tinggi }\end{array}$ & 2 & $\begin{array}{c}\text { Mangrove. } \\
\text { Pemukiman, } \\
\text { pelabuhan }\end{array}$ & 1 \\
\hline $\begin{array}{l}\text { Ketersediaan } \\
\text { air tawar }(\mathbf{k m})\end{array}$ & 3 & $<0,5$ & 4 & $>0,5-1$ & 3 & $>1-2$ & 2 & $>2$ & 1 \\
\hline
\end{tabular}


Strength (S) Mengungkapkan hal-hal yang menjadi kekuatan dengan tujuan memberikan penghargaan terhadap segala hal-hal positif yang dimiliki. Kekuatan ini yang terus dikembangkan untuk pengelolaan wisata pantai di masa depan. Faktor kekuatan (S) terkait dengan kesesuaian ekologis, daya dukung kawasan, infrastruktur, pengelola, sistem pengelolaan, usaha wisata, dan persepsi masyarakat terhadap pariwisata. Opportunities (O) Melakukan analisis terhadap lingkungan eksternal guna mengidentifikasi peluang terbaik yang dimiliki serta dapat. Hal ini mensyaratkan adanya cara pandang yang positif dalam memandang lingkungan eksternal yang berubah dengan sangat cepat. Faktor peluang (O) terkait dengan kebijakan pemerintah daerah, kunjungan wisatawan, kepuasan wisata, aksesibilitas, dan aspek ekonomi bagi pelaku usaha wisata. Aspirations (A) Para stakeholder berbagi aspirasi dan merancang kondisi masa depan yang diimpikan yang dapat menimbulkan rasa percaya diri terhadap pekerjaan maupun kelembagaan. Hal ini sangat penting guna menciptakan visi, misi serta nilai yang disepakati bersama, yang menjadi panduan bagi perjalanan pengelolaan wisata pantai menuju masa depan. Faktor aspirasi (A) terkait dengan kapasitas pengelolaan, dukungan pemerintah, sistem pengelolaan, fasilitas wisata, tata kelola kawasan, dan keterlibatan stakeholder dalam pengelolaan wisata. Results (R) Menentukan ukuran dari hasil-hasil yang ingin dicapai (measurable results) sebagai perencanaan strategis. Faktor hasil (R) yang terukur dirumuskan dari faktor kekuatan (S), peluang (O) dan aspirasi (A) yang melahirkan suatu perencanaan strategis sebagai alternatif strategi pengelolaan kawasan wisata.

\section{HASIL DAN PEMBAHASAN}

Data primer dan sekunder yang telah dikumpulkan kemudian dimasukkan ke dalam matriks kesesuaian untuk mengetahui kelas kesesuaian ekosistem sebagai objek wisata dan pengembangan wisata berkelanjutan. Masing-masing parameter di dalam matriks kesesuaian ini memiliki skor dan bobot yang berbeda berdasarkan tingkat kepentingan terhadap pengembangan wisata berkelanjutan. Kegiatan wisata yang di kembangkan hendaknya disesuaikan dengan potensi sumberdaya dan peruntukannya. Setiap kegiatan wisata mempunyai persyaratan sumberdaya dan lingkungan yang sesuai obyek wisata yang akan dikembangkan. Penentuan kesesuaian berdasarkan perkalian skor dan bobot yang diperoleh dari setiap parameter. Kesesuaian kawasan dilihat dari tingkat persentase kesesuaian yang diperoleh penjumlah nilai dari seluruh parameter. Hasil perhitungan Indeks Kesesuaian Wisata Pantai Ungapan pada tabel 3.

Tabel 3 Hasil pengamatan, pengukuran, dan analisis parameter kesesuaian wisata Pantai Ungapan

\begin{tabular}{clcccc}
\hline \multicolumn{1}{c}{ Parameter } & Bobot & Kategori & Skor & BxS \\
\hline 1. & Tipe Pantai & 5 & Pasir putih & 4 & 20 \\
2. & Lebar pantai $(\mathrm{m})$ & 5 & $\begin{array}{c}>15 \\
(18 \mathrm{~m})\end{array}$ & 4 & 20 \\
\hline 3. & Material dasar Perairan & 5 & Pasir & 4 & 20 \\
\hline 4. & Kemiringan pantai $(\%)$ & 4 & $10-15\left(8^{0}\right)$ & 3 & 12 \\
\hline 5. & Penutupan lahan pantai & 3 & $\begin{array}{c}\text { Semak belukar, } \\
\text { Lahan terbuka }\end{array}$ & 3 & 9 \\
\hline 6. & Ketersediaan air tawar $(\mathrm{km})$ & 3 & $<0,5$ & 4 & 12 \\
\hline TOTAL & & & & $\mathbf{9 3}$ \\
\hline
\end{tabular}


Berdasarkan tabel pengamatan, pengukuran, dan analisis parameter kesesuaian wisata Pantai Ungapan diketahui bahwa parameter tipe pantai, lebar pantai, material dasar perairan memperoleh skor 4. Kemiringan lereng, penutup lahan pantai dan ketersediaan air tawar mendapat skor 3. Pantai Ungapan memiliki keistimewaan garis pantai yang panjang, pasir yang bersih dan putih, serta ombak besar yang mempesona sehingga cocok untuk kegiatan rekrasi dan berkemah (camping). Pantai Ungapan juga berdekatan sistem perairan darat, yaitu muara sungai. Keberadaan sungai ini terletak di bagian kiri dari pintu masuk objek wisata. Muara sungai ini yang biasanya dimanfaatkan wisatawan untuk berenang dan bermain sepeda air, karena areanya cukup luas dan arusnya lebih tenang. Keadaan pantai ini juga masih terbilang terawat dan masih asri. Adapun hasil penilaian IKW kawasan ekowisata pantai Ungapan adalah $93 \%$.

Dari tabel 2 dan hasil perhitungan IKW dapat diketahui bahwa Indeks Kesesuaian Pantai Ungapan adalah 93\%. Berdasarkan perhitungan Indeks Kesesuaian Wisata yang telah dilakukan, Pantai Ungapan termasuk dalam katagori sesuai. Suatu kawasan wisata dapat dikatakan sesuai untuk dijadikan kawasan pantai apabila mempunyai indeks kesesuaian 77,78 - 100\%. Karena Pantai Ungapan menunjukkan angka 93\% maka wilayah tesrebut sesuai dijadikan kawasan wisata pantai. Kawasan pantai yang baik memang harus memenuhi kriteria-kriteria tertentu untuk dapat dikatakan sesuai.

Strategi pengembangan yang diasumsikan dapat mengembangkan secara efektif adalah metode SOAR. Metode SOAR merupakan komponen yang digunakan untuk perumusan rekomendasi tertentu. Dalam metode ini terdapat kekuatan, peluang, aspirasi, dan hasil yang dimiliki dan diinginkan penyelenggara pelayanan pariwisata Pantai Ungapan. Metode SOAR ini dibutuhkan adanya semangat optimisme dalam membangun dan mengupayakan peningkatan penyelenggaraan pelayanan pariwisata Pantai Ungapan dari berbagai pihak. Dalam hal ini mengharuskan pihak-pihak tersebut untuk mempunyai keinginan mengembangkan pariwisata Pantai Ungapan secara lebih baik dan optimal daripada sekarang. Berdasarkan hal itu, komponen SOAR yang telah diidentifikasi akan menghasilkan suatu solusi strategis sebagai rekomendasi bagi upaya perbaikan. Hal tersebut dibarengi dengan pengukuran kekuatan, dengan demikian akan dapat diketahui sampai sejauh mana usaha yang kita miliki untuk mencapai suatu tujuan (aspirasi) dan tujuan utama untuk menciptakan pariwisata yang ideal dapat tercapai.

Penentuan isi komponen-komponen yang ada dalam metode SOAR ini dilakukan dengan pengambilan data berdasarkan hasil pengukuran, pengamatan atau observasi, wawancara, dan studi literatur untuk mendapatkan data sekunder (lihat tabel 4). Berdasarkan observasi yang dilakukan dapat diuraikan dari komponen SOAR yang pertama yaitu Strength (S) yaitu : (1) Tingkat kesesuaian ekologi yang sesuai untuk pengembangan wisata dapat dilihat dari nilai IKW yaitu $93 \%$ atau sesuai untuk rekreasi pantai, (2) Ketersediaan fasilitas dan infrastruktur wisata yang cukup memadai, (3) Daya dukung kawasan baik, (3) Sistem pengelolaan wisata yang cukup baik ,yaitu dikelola dengan kerjasama PERHUTANI dan LMDH (Lembaga Masyarakat Desa Hutan), (4) Ketersediaan usaha untuk meningkatakan perekonomian seperti pemilik warung, persewaan perahu dll, (5) Persepsi masyarakat yang baik tentang ekowisata pantai ungapan dan (6) Ketersediaan kuliner khas ikan bakar yang dapat dijumpai di hampir semua warung. Kekuatan lain dapat dilihat dari daya tarik ekowisata Pantai Ungapan pada saat 
sore menjelang malam terdapat matahari terbenam yang sangat indah di Pantai Ungapan. Selain itu ditambah dengan pemandangan yang indah, gelombang, pepohonan, dan kawasan yang memadai membuat suasana menjadi tenang. Area di sekitar Pantai Ungapan juga memiliki banyak usaha untuk meningkatkan perekonomian masyarakat seperti usaha warung makanan, mushola, kamar mandi, perahu keliling, speed boad, persewaan motor dan sebagainya. Pengunjung juga memiliki persepsi yang baik akan Pantai Ungapan, mereka merasa senang dan bisa menghilangkan penat ketika berwisata di Pantai Ungapan. Keberagaman merupakan salah satu penguat daya tarik lokasi wisata bagi wisatawan (Purnomo, et al., 2019).

Tabel 4 Matrik SOAR pengembangan objek wisata Pantai Ungapan

\section{Kekuatan (strengths),}

1. Tingkat kesesuaian ekologi yang sesuai untuk pengembangan wisata untuk rekreasi

2. Ketersediaan fasilitas dan infrastruktur wisata yang cukup memadai

3. Daya dukung kawasan baik

4. Sistem pengelolaan wisata yang cukup baik

5. Ketersediaan usaha untuk meningkatakan perekonomian

6. Persepsi masyarakat yang baik

7. Ketersediaan kuliner khas ikan bakar

\section{Peluang (Opportunities)}

1. Pemerintah telah menyusun RIPPDA

2. Kunjungan wisatawan yang banyak setelah pemerintah daerah melakukan branding wisata Malang the heart of Java dan mecanangkan tahun kunjungan wisata Kabupaten Malang

3. Kepuasan wisata pengunjung yang baik

4. Aksesbilitas yang baik karena dekat Jalur Lintas Selatan (JLS)

5. Memberikan keuntungan ekonomi bagi para masyarakat yang membuka usaha dan LMDH

6. Ketersediaan layanan wifi internet yang disediakan pengelola
Aspirasi (Aspirations)

1. Peningkatan kapasitas pengelolaan dan dukungan pemerintah untuk meningkatkan kunjungan wisata

2. Peningkatan kualitas fasilitas dan infrastruktur wisata untuk meningkatkan kunjungan wisata

3. Penataan kawasan wisata untuk meningkatkan daya tarik wisata

4. Perencanaan pengelolaan pariwisata berkelanjutan

5. Pemberdayaan pelaku usaha wisata untuk meningkatkan daya tarik wisata

6. Penyelenggaraan event promosi wisata untuk meningkatkan kunjungan wisata

7. Penyelesaian konflik di kawasan ekowisata

\section{Hasil (Results)}

1. Mengoptimalkan seluruh potensi yang ada, untuk mewujudkan pengelolaan pariwisata berkelanjutan.

2. Melibatkan berbagai pihak untuk melakukan kerja sama dalam upaya peningkatan, perbaikan, menjaga dan optimalisasi.

3. Melakukan peningkatan daya tarik wisata yang ada dengan meningkatkan kualitas fasilitas dan infrastruktur terpadu untuk meningkatkan daya saing dalam menarik kunjungan wisatawan.

4. Pembangunan kemitraan pariwisata untuk meningkatkan percepatan pertumbuhan ekonomi dalam menunjang pendapatan daerah

Opportunitie (O) sama seperti halnya peluang atau kesempatan yang bisa di lihat oleh suatu wilayah yang penuh dengan berbagai macam kemungkinan dan peluang. Salah satu syarat bagi keberhasilan suatu objek wisata adalah kemampuannya memaksimalkan peluang yang dimiliki. Hal ini mensyaratkan adanya cara pandang yang positif dalam memandang lingkungan eksternal yang berubah dengan sangat cepat. Peluang yang sudah ada dan mendukung pengembangan ekowisata pantai Ungapan diantaranya adalah (1) pemerintah daerah telah menyusun RIPPDA, (2) Kunjungan wisatawan yang banyak setelah pemerintah daerah melakukan branding wisata Malang the heart of Java dan 
mencanangkan tahun kunjungan wisata Kabupaten Malang, (3) Kepuasan wisata pengunjung yang baik, (4) Aksesbilitas yang baik karena dekat Jalur Lintas Selatan (JLS), jalan menuju pantai ini juga telah bagus, apalagi adanya program pemerintah pembangunan jalur lintas selatan yang ada. Jalur lintas selatan merupakan akses yang paling membantu dalam menuju lokasi. Hal ini juga merupakan salah satu rencana pemerintah untuk mempercepat pertumbuhan ekonomi wilayah melalui pariwisata. Tujuannya agar mempermudah para wisatawan, (5) Memberikan keuntungan ekonomi bagi para masyarakat yang membuka usaha dan LMDH seperti persewan homestay, sewa perahu, dan fasilitas outbond, (6) Ketersediaan layanan wifi internet yang disediakan pengelola ekowisata Pantai Ungapan saat ini sudah memiliki jaringan koneksi internet yang bisa dibilang lancar, sehingga untuk mengadakan suatu kegiatan di Pantai Ungapan sangat cocok. Akses menuju pantai ini juga telah sangat bagus, apalagi adanya program pemerintah pembangunan jalur lintas selatan yang ada. Jalur lintas selatan merupakan akses yang paling membantu dalam menuju lokasi. Hal ini juga merupakan salah satu rencana pemerintah untuk mengembangkan potensi pariwisata pantai selatan, tujuannya agar mempermudah para wisatawan.

Aspirations (A), berbagi aspirasi yang bisa rancang guna memperbaiki kondisi masa depan yang diinginkan, yang dapat menimbulkan rasa percaya diri dan kebanggaan (1) Peningkatan kapasitas pengelolaan, dukungan masyarakat dan dukungan pemerintah untuk meningkatkan kunjungan wisata. Hal ini dapat terlihat dari komunitas yang mengelola pantai secara bersama-sama. dengan adanya dukungan dari pemerintah setempat dan masyarakat untuk mengembangkan pantai tersebut akan lebih mudah. Masyarakat banyak menyumbangkan tenaga dan fikiran guna meningkatkan wisatawan untuk datang ke Pantai Ungapan. (2) Peningkatan kualitas fasilitas dan infrastruktur wisata untuk meningkatkan kunjungan wisata, (3) Penataan kawasan wisata untuk meningkatkan daya tarik wisata. Hal yang terpenting yaitu melakukan penataan terhadap fasilitas wisata untuk menciptakan keasrian kawasan, memperluas kawasan wisata dengan menggarap kawasan sekitarnya yang potensial, dan mewujudkan kebersihan lingkungan kawasan objek wisata. Pengunjung sendiri mengharapkan pelengkapan sarana prasarana khususnya tempat bermain untuk anak. Kebersihan lokasi juga turut menjadi aspirasi mereka, (4) Perencanaan pengelolaan pariwisata berkelanjutan, (5) Pemberdayaan pelaku usaha wisata untuk meningkatkan daya tarik wisata, (6) Penyelenggaraan event promosi wisata untuk meningkatkan kunjungan wisata, (7) Penyelesaian konflik di kawasan ekowisata

Results (R) Berarti menentukan ukuran dari hasil-hasil yang ingin dicapai dalam perencanaan strategis atau strategi yang telah digunakan, guna mengetahui sejauh mana pencapaian dari tujuan yang telah disepakati bersama. Pengelola perlu menciptakan kesan yang baik, bisa digunakan untuk menarik wisatawan datang ke pantai lagi bahkan memberi tahu kepada rekan dan kerabat mereka untuk berkunjung. Perlu adanya pengelolaan pariwisata berkelanjutan agar dapat dinikmati dan dimanfaatkan dari generasi ke genarasi. Kerjasama berbagai pihak untuk melakukan dalam upaya peningkatan, perbaikan, menjaga dan optimalisasi ekowisata. Dengan adanya peningkatan jumlah wisatawan harus diimbangi dengan peningkatan sarana dan prasarana yang ada (Purnomo, et al., 2017). Hal ini dilakukan untuk meningkatkan daya saing dalam menarik kunjungan wisatawan. Selanjutnya adalah memperbanyak kerjasama dan kemitraan untuk 
mempromosikan ekowisata Pantai Ungapan agar dikenal luas. Selain itu wajib merawat kelestarian, pelayanan demi terjaganya alam dan kepuasan para wisatawan. Perlu juga ada memperhatikan untuk meningkatkan kesejahteraan pelaku ekonomi dalam pariwisata tersebut (Kholidiani, 2017).

Penentuan result yang ada juga mencantumkan tentang pariwisata berkelanjutan. Salah satu strategi yang ada dengan mengoptimalkan potensi yang ada, untuk mewujudkan pengelolaan pariwisata berkelanjutan. Alasan utama perlunya pariwisata berkelanjutan adalah agar potensi keindahan alam, pemanfaatan, pengoptimalan, serta kelestarian alam bisa terus digunakan sampai generasi selanjutnya. Pariwisata berkelanjutan bukanlah hal yang dapat dicapai dalam jangka pendek, atau dicapai secara parsial. Semua pemangku kepentingan perlu bergerak bersama secara konsisten dalam program jangka panjang menuju visi dan tujuan bersama.

Pariwisata berkelanjutan didefinisikan oleh UNWTO sebagai: "Pariwisata yang memperhitungkan secara penuh dampak ekonomi, sosial dan lingkungan sekarang dan yang akan datang, menjawab kebutuhan pengunjung, industri (pariwisata), lingkungan dan komunitas tuan rumah". Prinsip-prinsip keberlanjutan mengacu kepada aspek-aspek lingkungan, ekonomi dan sosio-budaya dalam pembangunan kepariwisataan, dan keseimbangan yang sesuai harus dibentuk antara ketiga dimensi tersebut untuk menjamin keberlanjutannya dalam jangka panjang. Kelestarian vegetasi, flora dan fauna yang ada di pantai harus dijaga dan tidak mengusiknya. Dengan tidak membuang sampah dan limbah ke laut, meminimalkan penggunaan bahan bakar minyak untuk perahu dengan mengganti yang lebih ramah lingkungan, menjaga habitat terumbu karang, menjaga kebersihan air dan pasir pantai. Hal-hal itu merupakan upaya agar pariwisata terus berlanjut.

\section{KESIMPULAN}

Potensi ekowisata pantai di Pantai Ungapan salah satunya adalah ekowisata kategori rekreasi, dengan nilai indeks kesesuaian kawasan (IKW) 93\% S1 (sangat sesuai). Pantai Ungapan sesuai dijadikan kawasan wisata rekreasi pantai. Kawasan pantai yang baik memang harus memenuhi kriteria-kriteria tertentu untuk dapat dikatakan sesuai. Kesesuaian wisata Pantai Ungapan Kabupaten Malang tergolong sesuai dengan indeks. Dari analisis SOAR, terdapat tiga alternatif strategi untuk mengembangkan objek wisata ini, yaitu (1) Mengoptimalkan seluruh potensi yang ada, untuk mewujudkan pengelolaan pariwisata berkelanjutan, (2) Melibatkan berbagai pihak untuk melakukan kerja sama dalam upaya peningkatan, perbaikan, menjaga dan optimalisasi ekowisata, (3) Melakukan peningkatan daya tarik wisata yang ada dengan meningkatkan kualitas fasilitas dan infrastruktur terpadu untuk meningkatkan daya saing dalam menarik kunjungan wisatawan, (4) Pembangunan kemitraan pariwisata untuk meningkatkan percepatan pertumbuhan ekonomi dalam menunjang pendapatan daerah..

\section{DAFTAR PUSTAKA}

Adi, Mustafa \& Ketjulan, 2013. Kajian potensi kawasan dan kesesuaian ekowisata terumbu karang Pulau Laras untuk pengembangan ekowisata bahari. Jurnal Mina Laut Indonesia, 1(1), pp. 49-60. 
58 Insani, dkk, Studi kesesuaian dan strategi pengelolaan ekowisata Pantai Ungapan...

Ali, 2004. Pemanfaatan potensi sumberdaya pantai sebagai obyek wisata dan tingkat kesejahteraan masyarakat sekitar lokasi wisata (Studi kasus di kawasan wisata Pantai Kartini Jepara), Semarang: Program Pascasarjana Universitas Diponegoro.

Domo, Zulkarnaini \& Yoswati, 2017. Analisis Kesesuaian dan Daya Dukung Kawasan Wisata Pantai (Studi Pantai Indah Sergang Laut di Pulau Singkep). Dinamika Lingkungan, 4(2), pp. 109-116.

Fandeli, 2000. Pengusahaan pariwisata. Yogyakarta: Gadjah Mada University Press.

Hutabarat, et al., 2009. Pengelolaan pesisir dan laut secara terpadu. Bogor: Pusdiklat Kehutanan, SECEM dan Korea International Cooperation Agency.

Kholidiani, S., 2017. Peran Wisata Religi Makam Gus Dur Dalam Membangun Kehidupan Sosial Ekonomi Masyarakat Di Sekitar Pondok Pesantren Tebuireng Jombang. Jurnal Teori dan Praksis Pembelajaran IPS, 2(1), pp. 41-45.

Purnomo, A., Ruja, I. N. \& Irawan, L. Y., 2017. Typology of Tourist Bromo Tengger Semeru National Park as a Basic Planning Integrated Tourism Design. Bandung, IOP Conf. Series: Earth and Environmental Science.

Purnomo, A., Wiradimadja, A. \& Kurniawan, B., 2019. Diversification of tourism product in KSPN Ijen. Jember, IOP Conference Series: Earth and Environmental Science.

Senoaji, G., 2009. Daya Dukung Lingkungan dan Kesesuaian Lahan dalam Pengembangan Pulau Enggano di Bengkulu. Jurnal Bumi Lestari, 9(2), pp. 159-166.

Stavros \& Hinrichs, 2009. Thin book of SOAR: building strenghts-based strategy. Bendor: Thin Book Publishers.

Yulianda, 2007. Ekowisata bahari sebagai alternatif pemanfaatan sumberdaya pesisir berbasis konservasi, Bogor: Institut Pertanian Bogor. 